
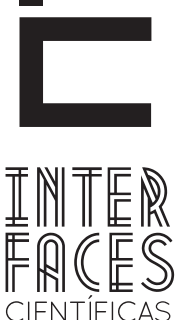

HUMANASE SOCIAIS

\title{
VIOLÊNCIA OCULTA: A FALTA DE SEGURANÇA NAS EDIFICAÇÕES VERTICAIS DE ARACAJU
}

Geovan Lima Fontes ${ }^{1}$

Vania Fonseca ${ }^{3}$

\section{RESUMO}

Aracaju, cidade com rápido crescimento vertical, tem muitas edificações sem a necessária dotação de infraestrutura físico-arquitetônica, equipamentos e treinamento de brigadas de incêndio para evitar e combater sinistros, especialmente incêndio e pânico. A população, desavisada dessa violência que se esconde dentro das edificações e que pode eclodir a qualquer momento, permanece confiante, sem se preocupar com medidas preventivas e, ainda, muitas vezes altera as condições de segurança, obstruindo rotas de fuga como escadas, descuidando da manutenção e retirando do lugar equipamentos como extintores, bico de mangueiras e outros, por ignorar a sua importância em caso de necessidade imediata. 0 artigo, baseado em levantamentos de campo por meio de observação direta e documentos de vários tipos, analisa as condições das edificações e o seu entorno, desde as mais antigas até as mais recentes, considerando a legislação de várias datas, que alteraram as normas de segurança, e aponta a necessidade de serem estabelecidas normas específicas para Aracaju e o Estado de Sergipe, de forma a facilitar o trabalho dos órgãos responsáveis pelo licenciamento de obras e a sua periódica fiscalização, bem como por fazer cumprir a exigência de treinamento de brigadas de incêndio, dentre outras, de forma a diminuir o potencial de ocorrência de incêndios e suas consequências danosas para os seres humanos e o patrimônio, inclusive patrimônio histórico, que é imaterial.

\section{PALAVRAS-CHAVE}

Segurança Contra Incêndio. Aracaju. Violência Oculta. 


\section{ABSTRACT}

Aracaju city with rapid vertical growth, has many buildings without the necessary allocation of physical and architectural infrastructure, equipment and training of fire brigades to prevent and combat claims, especially fire and panic. The population is unaware of such violence that lurks within the buildings and can erupt at any time, remains confident without worrying about preventive measures and also often changes the security conditions, blocking escape routes such as stairs, neglecting the maintenance and taking place equipment like extinguishers, hose nozzle and others, because their importance is ignored in case of immediate need. The article, based on field surveys through direct observation and documents of various types, analyzes the conditions of the buildings and their surroundings, from the oldest to the most recent, considering the rules of various dates, which changed safety standards, and points to the need to set specific standards for Aracaju and Sergipe State, in order to facilitate the work of the agencies responsible for the licensing of their works and periodic inspection, as well as to meet the requirement of training of fire brigades, among other in order to reduce the potential for fire occurrence and its harmful consequences for humans and heritage, including intangible heritage.

\section{KEYWORDS}

Fire safety. Aracaju. Hidden violence.

\section{RESUMEN}

La ciudad de Aracaju con crecimiento vertical rápido, tiene muchos edificios sin la necesaria asignación de la infraestructura física y arquitectónica, equipamiento y capacitación de los cuerpos de bomberos para prevenir y combatir las reclamaciones, especialmente incendio y de pánico. La población no es consciente de este tipo de violencia que se esconde dentro de los edificios y puede estallar a cualquier momento, y mantienen su confianza sin se preocupar acerca de las medidas preventivas. También, a menudo, se cambian las condiciones de seguridad, bloqueando rutas de fugas de las vías de evacuación, tales como escaleras, dejando de lado el mantenimiento de los equipos, sin decir de la retirada de sus sitios de los extintores, mangueras y por ignorar su importancia en caso de necesidad inmediata. El artículo, basase en estudios de campo a través de la observación directa y documentos de diversos tipos, analizando sus condiciones en los edificios y su entorno, desde la más antigua a la más reciente, teniendo en cuenta las reglas de varias fechas, que cambiaron las normas de seguridad, y apunta a la necesidad de establecer normas específicas para Aracaju y el estado de Sergipe, con el fin de facilitar la labor de los organismos encargados de la concesión de licencias de sus obras e inspecciones periódicas, así como para cumplir con el requisito de la formación de los cuerpos de bomberos, entre otros con la finalidad de reducir la posibilidad de ocurrencia de incendios y sus consecuencias perjudiciales para los seres humanos y al patrimonio, incluso el patrimonio que es inmaterial.

\section{PALABRAS CLAVE}

Seguridad contra incendios. Aracaju. Violencia camuflada. 


\section{INTRODUÇ̃̃OO}

A tendência à verticalização das construções de edifícios, seja para fins comerciais, residenciais ou outros, vem crescendo no mundo todo. Esse ambiente construído ganha proporções por vezes muito grandes, o que dificulta o atendimento de sinistros e muitas vidas têm sido perdidas decorrentes de problemas com segurança, especialmente contra incêndios.

\begin{abstract}
No Brasil as perdas por incêndios em edificações têm aumentado em importância, visto que os sinistros vêm envolvendo cada vez maiores riscos, em face da urbanização brasileira. Com o consequente aumento dos riscos de incêndio, será necessário um investimento cada vez maior na área de segurança contra incêndio e pânico (FERNANDES, 2010, p. 13)
\end{abstract}

Novas tecnologias em Segurança Contra Incêndio (SCI) de tendência internacional desenvolvidas na Europa, Estados Unidos da América e Japão vêm sendo estudadas e analisadas, também, no Brasil, sendo que na Região Sudeste do país está estabelecidaa maior parte dos laboratórios de ensaios para pesquisa científica em segurança contra incêndio.Como objetivos das novas tecnologias deve-se pensar sempre na meIhoria da SCl, relacionando-a com os princípios básicos: aumentar a segurança humana e diminuir as perdas materiais (SEITO, 2008).

Cada tragédia acontecida é uma experiência vivida, das quais muitas lições são aprendidas. Como em diversos países, o Brasil registrou histórias trágicas no tocante a grandes incêndios acontecidos por falta de prevenção adequada, contextualizando na ineficiência da proteção à vida e ao ambiente.

O Brasil, apesar de levantamentos estatísticos sofríveis, é o segundo país do mundo em número de vítimas de incêndios. Cabe salientar, todavia, que os dados estão quase que na totalidade, restritos às chamadas dos corpos de bombeiros. Como só $5 \%$ dos municípios possuem grupamentos de incêndio é possível perceber a subinformação que prejudica os dados oficiais disponíveis (BRASIL, 1995, p. 14)
Até a década de 1970 do século XX, no Brasil havia pouca preocupação com a proteção à vida humana em casos de incêndios, até que dois grandes incêndios em edificações verticalizadas ocorridas em São Paulo chamaram a atenção dos brasileiros e de todo o mundo, que foram os casos do Edifício Andraus, em 1972, e Edifício Joelma, em 1974, nos quais pereceram um total de 195 pessoas. As consequências advindas desses dois grandes incêndios foram motivadas, basicamente, pela ausência de escada de segurança para fuga das pessoas em caso de emergência de incêndio, pela facilidade de propagação das chamas e pela dificuldade de salvamento (SEITO et al, 2008, p. 20-21).

Fatores urbanísticos, portanto externos às edificações, também devem ser observados, pois contribuem para a garantia da incolumidade da população fixa, que são todas as pessoas que fazem permanência efetiva na edificação, e da população flutuante, composta pelas pessoas que têm a permanência temporária ou esporádica na edificação. Um desses fatores está relacionado à malha urbana,como o distanciamento entre edificações para evitar a propagação do incêndio; o distanciamento da edificação em relação ao grupamento do Corpo de Bombeiros mais próximo, para obter um melhor tempo resposta relacionado ao atendimento em ocorrências; o estabelecimento de hidrantes urbanos, que facilitam 0 abastecimento das viaturas dos Bombeiros; a largura das vias de acesso à edificação, que facilitam as manobras dos caminhões tanques, escadas e plataformas do Corpo de Bombeiros.

Além disso, especialmente vinculado aos grandes edifícios, deve ser demarcado estacionamento para o estabelecimento das viaturas dos Bombeiros, com o intuito de realizar as missões de combate e salvamento de forma satisfatória, bem como devem ser padronizadas larguras e alturas do portão de entrada, de forma a prover o acesso da maior viatura da corporação de Bombeiros, que dispõe de Plataforma Aérea (SEITO et al., 2008, p. 126-127). 
No âmbito das questões de segurança em edificações pode-se constatar - e convém enfatizar - que as escadas de segurança em prédios altos, de construção mais antiga, muitas vezes foram esquecidas pelos arquitetos que não se preocuparam em planejar uma rota de fuga segura para a população fixa ou circulante que utiliza a edificação. Nas construções mais recentes, observa-se a falta de áreas internas da edificação que deveriam ser necessárias para a realização de manobra das viaturas do Corpo de Bombeiros, que muitas vezes se encontram impedidas pelas coberturas de vagas de garagem que beneficiam os usuários, mas fogem das regras de segurança. Esse fato é observado principalmente em edifícios residenciais.

Telmo Brentano (2010), em seu livro sobre a segurança contra incêndio no projeto de edificações, descreve que a proteção mínima contra o fogo, de forma a resguardar as pessoas e o patrimônio, pode ser representada por três medidas importantes e indispensáveis: a) bom projeto arquitetônico; b) adequados equipamentos de combate a incêndio; c) brigada de incêndio capacitada. Essas três medidas definidas por Brentano são mutuamente dependentes, pois uma não funcionará sem a outra. Ter equipamentos de combate a incêndio sem treinar e habilitar pessoas para o seu uso não faz sentido, como também não faz sentido ter saídas de emergência sem que os usuários da edificação tenham orientação para usá-las em situações de emergência.

\section{A LEGISLAÇ̃̃o DE SEGURANÇA VINCULADA À VERTICALIZAÇÃO EM ARACAJU}

Em Sergipe, na década de 1970 do século passado, os riscos de desastres aconteceram em consonância com a mesma disponibilidade das inadequações de prevenção e proteção na segurança contra incêndio em que se apresentava o país naquela época. Aracaju era regrada pela Lei Municipal $n^{\circ} 13$, de três de junho
Além disso, não adianta ter equipamentos e pessoas treinadas se não houver um bom projeto de incêndio, visto que esse projeto retrata o mapa descritivo dos tipos e localização da cada aspecto preventivo do sistema de segurança. 0 projeto deve evitar que o fogo se propague, deve-se promover o isolamento dos pavimentos ou andares, com saídas de emergências suficientes, bem projetadas, adequadamente dimensionadas, sinalizadas e iluminadas, que garantam a segurança dos moradores e demais usuários. Os equipamentos de combate ao fogo devem estar em condições adequadas de manutenção e conservação, para que possam ser utilizados plenamente quando necessário.

A brigada de incêndio, também considerada condição fundamental, deve ser formada por pessoas da própria edificação, capacitados para, em caso de sinistro, atuar no combate ao fogo e na orientação da saída dos usuários do edifício, podendo, também, atuar nos primeiros socorros às pessoas que se machucarem, e prestar apoio para que seja evitado o pânico, até chegada do pessoal do Corpo de Bombeiros. Mas essa brigada de incêndio não deve atuar apenas quando ocorre um sinistro; ela deve, também, ser responsável pela prevenção de problemas por meio de tarefas de fiscalização para que não ocorram falhas no sistema de segurança, o que reflete em manutenção da segurança e confiança por parte dos usuários da edificação.

de 1966 (ARACAJU, 1966), que estabelecia as diretrizes para a consecução do Código de Obras do município, referenciando no seu capítulo III sobre a planta de situação dos edifícios e seus elementos específicos, como a posição da edificação, taxa de ocupação do terreno, a sua relação com edificações vizinhas e 
outras. Essa mesma lei, em seu capítulo XII, citava a autoridade do Corpo de Bombeiros como órgão fiscalizador, na competência de prevenir incêndio em edificações e depósitos de materiais inflamáveis ou explosivos. Mas nela não foram inseridos os preventivos que fundamentavam a segurança das pessoas nas edificações, tipo saídas de emergências, e também, os treinamentos às pessoas dos prédios para agir em caso incêndio.

Desta forma o município de Aracaju estava, naquela década, entre os anos de 1970 a 1980, à deriva da sorte, mesmo com os exemplos de grandes incêndios ocorridos no país. Mas, o Estado de Sergipe não se absteve de formular questões inerentes a segurança, e passados trinta e três anos tomou-se a iniciativa de criar, em 22 de dezembro do ano 1999, a Lei Estadual 4.183 que se refereao Código de Segurança Contra Incêndio e Pânico (COSCIP), o qual estabelece e define critérios acerca de sistemas de segurança contra incêndio e pânico para as edificações no estado de Sergipe, que passou a complementaro Código de Obras de Aracaju.

Na primeira década do século XXI o COSCIP já se mostrou inadequado na prevenção de incêndios em edificações, em virtude do aumento elevado dos riscos de incêndio apresentados pelo desenvolvimento tecnológico e urbanístico da cidade; por isto, caiu em desuso, passando a ser observados os embasamentos das normas (NBRs) da Associação Brasileira de Normas Técnicas (ABNT). As normas da ABNT garantem a segurança de todos os produtos e serviços gerados no país. Essa substituição dos preceitos legais pelos normativos, embora permitam melhor adequação às orientações, traz um grande problema, pois as normas apenas recomendam, enquanto que as leis determinam obrigações.

A falta de legislação que determine a obrigatoriedade de obediência às orientações das Normas Brasileira Regulamentadoras (NBR), impedem fiscalização e punição, o que, na prática, se traduz em sérios problemas para a prevenção e combate a incêndios (BRENTANO, 2010). Em Sergipe, a Lei 4.183, estabelece que:

\begin{abstract}
Art. 28 - As normas vigentes, emitidas pela Associação Brasileira de Normas Técnicas - ABNT, pelo Departamento Nacional de Combustíveis - DNC, pelo Instituto de Resseguros do Brasil - IRB, e pelo ministério do trabalho, que tenham relação com a segurança contra incêndio e pânico, poderão ser adotadas plena ou parcialmente, ou servirem de base para dispositivos de normas próprias, a serem definidas em regulamentação à presente Lei (SERGIPE, 1999).
\end{abstract}

Atualmente, servindo como base o artigo 28, em Sergipe estão sendo utilizadas para a implantação da segurança contra incêndio as normas da ABNT, sendo utilizadas como parâmetro para a solução dos problemas de prevenção e fiscalização. Mas há a necessidade da criação de uma lei única a todos os estados federados, pois, desta forma, será evitado que se construam leis estaduais em forma de "colchas de retalhos" devido à diversidade de documentos legais e de normas brasileiras que regem as atividades técnicas desta área do conhecimento.

O bem-estar das pessoas e a preservação do ambiente estão dependentes das várias normas que se regram e fundamentam a segurança contra incêndio e pânico, como a NBR 9077:2001 que fixa as condições das rotas e saídas de emergências em edifícios, com caminhos seguros e desobstruídos para a fuga em caso de emergência. Essa norma determina até o número de saídas de emergências necessárias para a fuga das pessoas, define a sua localidade, estima a capacidade de pessoas que deverão fugir por cada saída, e orienta aos populares que deixem sempre esses caminhos de fuga desobstruídos.

A desocupação dos usuários de uma edificação vertical é realizada pelas escadas de emergência que garantem um caminho seguro por meio de suas portas corta-fogo, sendo que, segundo Berto (1998), as escadas estão vinculadas a quatro elementos do sistema global de proteção, com o objetivo de proporcionar a 
desocupação segura da edificação, rapidez, eficiência e segurança nas operações de resgate das pessoas e precaução contra colapso estrutural.

As normas NBR 15219:2005 e NBR 14276:2006 apresentam recomendações de segurança para um edifício, sendo a primeira para elaboração de plano de emergência que inclui dimensionamento de grupos de usuários e distância que deverão percorrer até um local seguro, faz a previsão de saídas alternativas para serem usadas quando uma saída estiver bloqueada, indica os locais da existência dos alarmes e das botoeiras que acionam o sistema desses alarmes de incêndio, bem como os locais em que devem ser instaladas as luminárias e as sinalizações de emergências e identifica os equipamentos extintores e hidrantes que estarão prontos para serem operados na condição de combater ao princípio de incêndio. Além disso, alerta para os perigos e riscos existentes, classificando-os de acordo com suas especificidades dentro de cada área de risco. A segunda recomendação versa sobre treinamento e dimensionamento de brigadas de incêndio, sem o que todo o equipamento instalado não será adequadamente utilizado.

Essas e outras normas formam um arcabouço normativo que recomendam desde os cuidados arquitetônicos e de construção, até providências de manutenção e capacitação de recursos humanos para a prevenção e proteção contra incêndios e explosão.

\section{AS CONDIÇÕES DE SEGURANÇA NAS EDIFICA- CÕES VERTICAIS DE ARACAJU}

A condição para assumir as responsabilidades no tocante aos riscos de incêndio e explosão ou desabamento em uma edificação baseia-se não somente na cultura da população, mas, também, no dinamismo apresentado entre os materiais combustíveis inflamáveis dispostos no ambiente, na elaboração dos projetos elétricos e nos projetos de construção. Por isso, pode-se afirmar que nem todas as edificações podem apresentar riscos iguais, pois há uma dinâmica de todos os elementos que compõe o complexo estrutural, que estão vinculados a maior ou menor quantidade de materiais inflamáveis, os riscos do sistema elétrico e os curtos-circuitos provenientes da falha de projeto e as fissuras em lajes e paredes que poderão ocorrer devido à má elaboração de projeto de engenharia.

É de fundamental importância que durante o processo de construção todos os responsáveis pelas edificações obedeçam aos requisitos básicos da segurança contra incêndio, desabamento ou explosão que são: elaborar um bom projeto com profissional qualificado e habilitado; definir uma quantidade de material combustível inflamável que não ofereça grandes riscos ao local; implantar um sistema de segurançae orientação de pessoas referentes à prevenção.

Com base nas informações precisas sobre a segurança contra incêndio em Aracaju, percebe-se que os edifícios mais antigos com mais de quatro andares não tiveram suas construções orientadas por normas de prevenção e combate a incêndio, pois foram construídos antes da promulgação da Lei n 4183/1999 que estabeleceu o Código de Segurança contra incêndio de Sergipe, como o Edifício Valter Franco que é uma edificação com cinco andares e de uso misto, comercial e de serviços, construído da década de 1950; o Hotel Palace de Aracaju, com treze andares e hoje só ocupado no pavimento térreo por pequenos estabelecimentos comerciais; o Edifício Estado de Sergipe, com 28 andares ocupados por órgãos e instituições 
públicas; eo prédio do Instituto Nacional de Seguridade Social (INSS) hoje totalmente desocupado, todos estes construídos na década de 60 do século XX.

Outros prédios construídos antes da promulgação da Lei 4.183/1999 que merecem destaque são o Palácio da Justiça e a Assembléia Legislativa, na década de 1970, o Edifício Atalaia, primeiro edifício residencial de Aracaju, construído no início da década de 1980. Essas edificações, embora já tenham sido construídas segundo a orientação do Código de Obras de Aracaju, não tiveram a orientação da legislação sergipana que estabeleceu critérios acerca de sistemas de segurança contra incêndio e pânico para edificações. Essas edificações, além de não terem sido contempladas com cuidados adequados contra incêndio e pânico durante a sua construção, nem sempre são adequadamente conservadas, surgindo vários problemas que ameaçam a integridade das edificações e da população que as utiliza ou daqueles que passam nas suas imediações. Esse é o caso do Hotel Palace de Aracaju, desativado desde a década de 1990, mas que ainda tem funcionando várias lojas e oferecimento de serviços no pavimento térreo.

O Conselho Regional de Arquitetura e Engenharia de Sergipe teve a iniciativa de ofertar a denúncia ao Ministério Público, apontando a falta de manutenção e os desgastes apresentados pela edificação, que estariam propícios a desabamentos; mas até o momento não foi tomada nenhuma providência para reverter a situação denunciada (SILVA, 2009). Na visão de SANTOS (2004, p. 258), “Não é nada boa a condição que se encontra o edifício que abrigou o Hotel Palace de Aracaju. Quem passa pelas ruas pode observar que ocorre um processo de esfarelamento em sua estrutura externa”.

No mês de maio de 2002 houve registro da queda da marquise do prédio onde funcionava o Hotel Palace de Aracaju, novo alerta para as autoridades públicas. Mas apesar das muitas denúncias, inclusive pela mídia, a situação desse prédio em julho de 2012 permanece, com tendências a maiores agravos, com descaso das autoridades responsáveis pela reversão dessa situação de constante e eminente perigo.

Outro prédio erguido na região central de Aracaju, onde funcionou o Instituto Nacional de Seguridade Social (INSS), apresentou muitos problemas, como perigo de incêndio e de eventos catastróficos. Laudos já mostraram pontos de infiltração em alguns pilares e, embora a Coordenadoria de Defesa Civil Estadual descarte a possibilidade de desabamentos da estrutura, a placa do revestimento externo do prédio está deteriorada podendo ter pedaços descolados, o que põe em risco a população. Deve ser levantado que, no caso de incêndio nessa edificação, as condições de segurança quanto a desabamento podem ser bruscamente alteradas para pior.

Os demais prédios construídos no século $X X$ apresentam riscos que não poderiam ser ignorados e, embora sejam constantes as denúncias, nenhuma ação preventiva vem sendo desenvolvida, se configurando uma situação de tragédia anunciada. Por mais que a segurança seja primordial em uma edificação vertical, o retrato da época não identificou essa preocupação, pois a adequação dos edifícios para proteção contra eventos emergenciais de incêndio e pânico somente se deu a partir do ano 1999, no Estado de Sergipe. E ainda assim, devido à obsolescência das orientações dessa lei, nem sempre se adéquam às necessidades da prevenção e controle de eventos indesejados. Assim, os perigos permanecem ocultos nessas edificações.

As edificações verticais definidas para utilização por órgãos públicos foram pioneiras e tiveram maior prevalência na questão de desenvolvimento urbano. Os edifícios multifamiliares passaram a ser construídos na década de 1980, mas a aceleração das construções com mais de quatro andares para uso residencial só passou a ocorrer no final do século XX com grande intensificação no século XXI. 
Os edifícios multifamiliares apresentam como peculiaridade população fixa e período de estada permanente, situação diferente dos prédios comerciais ou industriais que tem permanência periódica de usuários, restritos basicamente a horário comercial ou expedientes administrativos de instituições/ órgãos públicos. As edificações de uso público parecem estar mais sujeita a danos em sua estrutura, bem como a quebra das regras de segurança, devido à heterogeneidade de entendimentos sobre perigos e proteção, aliada a alterações no ambiente construído para atendimento da necessidade de funcionamento da instituição. Assim, pouco adianta empregar esforços contra os perigos que possam destruir uma edificação e seus usuários, se os gestores desprezarem as normas de segurança, muitas vezes respaldados na justificativa de necessidade de serviço e na falta de sentimento de responsabilidade para com o patrimônio público, que não é sentido como sendo do conjunto dos cidadãos.

Essas considerações resultam da observação dos diversos perigos que existem na cidade de Aracaju, quando se trata de edifícios verticalizados, sejam comerciais, industriais, ou multifamiliares. Para estudiosos e profissionais da segurança contra incêndio e pânico, hoje esses prédios são vistos como atentados à segurança da população, devendo se adequar às condições mínimas exigidas pelas normas e leis, de forma a atender a necessidade de segurança da população, especialmente dos seus usuários, que não têm noção do perigo a que estão expostos diuturnamente.

Embora não seja possível comparar as edificações construídas logo após a metade do século XX e as que foram construídas no final da década de 1990, início do século XXI, alguns equipamentos de segurança deveriam ser instalados nos prédios mais antigos, sem a proteção de isolamento de risco entre edificações que, devido à crescente e acelerada urbanização, se torna cada vez mais necessária, pois os prédios estão cada vez mais próximos uns dos outros. Esses prédios, também, não dispõem de isolamento entre os anda- res, pois eram praticamente inexistentes as escadas de emergência ou escadas enclausuradas com portas corta-fogo, que evitam o fogo passar de um andar para o outro, além de não ter sistema de controle da fumaça que permita extrair a fumaça do ambiente que estiver sinistrando.

Além desses problemas, diretamente vinculados à concepção arquitetônica dos prédios mais antigos, outras providências deveriam ser alvo de preocupação a fim de minimizar os riscos de incêndio e pânico como a colocação de iluminação de emergência, sinalização, indicação da localização dos equipamentos de combate a incêndio, sistema de detecção de alarmes de incêndio. $E$ todos esses equipamentos devem passar por revisão/manutenção periódica, sem o que não se justifica a sua existência e, pior, dá uma falsa sensação de segurança aos usuários da edificação.

Ainda outra questão bastante séria é a das centrais de gás liquefeito de petróleo (GLP), instaladas nos prédios, quase sempre sem o adequado projeto de segurança, mas apenas seguindo orientações de utilização da empresa prestadora do serviço, sem a realização de testes periódicos de estanque idade para identificar qualquer tipo de vazamento do gás.

Atualmente Aracaju está assistindo a substituição do GLP pelo Gás Natural (GN), produto considerado mais seguro que o próprio GLP, pois enquanto o primeiro é de difícil dissipação quando é vazado da tubulação e se concentra nas áreas mais baixas, por ser um gás mais pesado que o ar, o GN se apresenta de forma contrária, tem maior poder de dissipação do local e com isto poderá oferecer menos perigo aos usuários. Mas o sistema de abastecimento com GN também precisa passar por verificações periódicas e ter realizada a manutenção adequada.

O sistema de extintores, equipamento exigido há mais tempo, vem sendo instalado tanto nas edificações mais antigas quanto nas mais novas, mas nem sempre são observadas as datas de vencimento da 
validade ou a pressão mínima necessária para o seu correto funcionamento e, muitas vezes é observada a ausência desses tipos de equipamentos nos locais para eles reservados. Os sistemas de hidrantes, mesmo quando existem, se apresentam mal dimensionados, por vezes colocados em posição inadequada que impede o seu uso, e geralmente não há pessoal preparado para manuseá-los. A falta de brigada de incêndio é uma situação crítica, sendo fundamental ter pessoal treinado para combater pelo menos o princípio de incêndio, ou retirar os moradores do edifício com segurança. Este fato não está relacionado somente às edificações antigas, mas também, às modernas. Brigada de incêndio é uma exigência da norma da ABNT de 2006, a NBR 14276 e, como o outro fator de proteção, é considerado essencial.

$\mathrm{Na}$ atualidade, mesmo com a implantação de projetos de segurança, é comum encontrar, nas edificações verticalizadas, o sistema de segurança ineficaz por atos de negligência, imperícia ou imprudência dos usuários daquele local, como é o caso de portas corta-

\section{CONSIDERACÕ̃ES FINAIS}

0 princípio da verticalização em Aracaju, que começou logo após meados do século XX, vem se acelerando e, devido ao não cumprimento das normas de segurança, faz aumentar os riscos de incêndio. As normas de segurança devem ser obedecidas e seu atendimento deve ser periodicamente atualizado, pois elas são constantemente renovadas para atender o dinamismo do avanço da tecnologia que, muitas vezes, sobrecarrega o sistema de segurança instalado durante a construção das edificações, tais como o uso de equipamentos de vários tipos, inclusive aparelhos de ar condicionado cuja utilização vem sendo cada vez mais comum devido ao aquecimento global e, em especial, aquecimento das zonas urbanas decorrente de ilha de calor reflexo da crescente densidade das edificações e da pavimentação asfáltica. -fogo que ficam abertas, sabendo-se que tem grande utilidade para proteger a edificação da propagação do incêndio por convecção, por meio dos gases aquecidos, da irradiação por meio das ondas caloríficas das chamas, e também protege as pessoas quando estiverem fugindo do incêndio.

Nas caixas de hidrantes vem sendo encontrados objetos estranhos como sombrinhas, roupas, bornais, latas de refrigerantes, menos os acessórios que auxiliam na composição da linha de combate. Os extintores mal sinalizados, danificados, sem carga ou fora do local a eles destinados; luminária de emergência com defeito; hidrantes, rota de fuga e extintores obstruídos; saídas de emergências insuficientes ou inexistentes; bomba de incêndio com defeito; escadas de emergência servindo de depósito de caixas e tralhas fora de uso. Esses e outros problemas fragilizam ou inutilizam o sistema de prevenção e combate a incêndio e pânico, violando ou negligenciando a segurança nas edificações verticalizadas e tornando ineficaz todoo sistema de proteção.

Os projetos de arquitetura e engenharia, inclusive hidráulica e elétrica devem ser obrigatoriamente cobrados e fiscalizados, pois precisam ser considerados como um investimento que garante a segurança e a proteção de vidas e bens. Cabe aos arquitetos, engenheiros e urbanistas efetuarem seus projetos, pensando nas maiores complexidades possíveis, e devem atuar na elaboração de projetos com visão interdisciplinar e, se possível com a colaboração de diferentes profissionais, pois somente arquitetos, engenheiros e urbanistas não terão a competência de garantir o conhecimento pleno da segurança contra incêndio nas edificações, necessitando de outros tipos de profissionais. 
O responsável da edificação deverá também contribuir para a execução desse projeto, entendendo a importância da correta elaboração e execução do projeto para a segurança da edificação que estiver sendo construída. É interessante que o responsável pela edificação faça uso de empresas especializadas em elaborar projetos, composta por especialistas com visão interdisciplinar, que possam, efetivamente, garantir a elaboração de projetos adequados ao uso a que se propõe.

Para análise de projetos de segurança contra incêndios o Corpo de Bombeiros deve instituir, em seu quadro efetivo, militares com formação nas diversas áreas de conhecimento, com a competência para identificar erros e aplicar as normas de forma padronizada.

Após o projeto de uma obra ter sido analisado pelos setores competentes, a edificação deverá implantar seu sistema de prevenção de acordo com o projeto aprovado, passando por um processo de vistoriaque autorizará o seu funcionamento ou solicitará às adequações que se fizerem necessárias.

Os edifícios construídos há muito tempo e que foram expostos a intempéries ao longo dos anos, tendo desgastadas suas fachadas, enfraquecidos seus pilares diante da corrosão consequente da maresia que existe na cidade de Aracaju, devem ser revitalizados e, se isso não puder ser feito, devem ser demolidos, pois a segurança da população deve sobrepor-se à questão patrimonial. As construções do século XX e XXI embora causem menor preocupação, devem ser fiscalizadas conforme estabelece a Lei 1.474 de 16/06/1989 alterada pela lei 2.765 de 30/12/1999 (Aracaju, 1999), que exige para o município de Aracaju, que a cada cinco anos seja feita a elaboração de Laudo de Vistoria das Condições de Manutenção do Imóvel. 0 cumprimento a essa legislação necessita ser fiscalizado pelas autoridades competentes e o valor das multas, irrisório, precisa ser revisto, pois inibe a burla da lei, especialmente, porque a contratação de engenheiro de segurança para a elaboração da vistoria é muitas vezes superior ao valor da multa, com o agravante que a multa só ocorre se houver denúncia, pois a fiscalização não é efetiva.

Na cobrança da manutenção e instalação aos preventivos de segurança contra incêndio e pânico, as empresas de manutenção de extintores deverão ser fiscalizadas para não forjar os princípios da legitimidade de produtos a serem utilizados ao combate do foco de incêndio. Além disso, todos os funcionários e os moradores que compuserem a brigada de incêndio devem saber do princípio de funcionamento de cada tipo de extintor, aplicando de forma correta do agente extintor ao tipo de material que estiver queimando.

Deve ser observado frequentemente se as mangueiras de incêndio estão nas caixas de hidrantes, identificada a existência dos acessórios de combate como é o caso do esguicho e chave de mangueiras, pois, é comum não estarem no local devido, pois o metal com que são fabricados chama a atenção de indivíduos menos escrupulosos, que costumam subtraí-los, muitas vezes para a venda. Com relação a esse fato, a norma NBR 12693:2010 já permite que as caixas de hidrantes possam ser trancadas a chave, desde que essa chave fique disponível em local do conhecimento de todos da edificação. Com essa atitude, até os próprios moradores e funcionários terão dificuldade de colocar materiais desnecessários na caixa de hidrante, evitando estragos ou impedimentos na hora do manuseio desse preventivo.

As rotas de fuga devem estar sempre fiscalizadas para que seja evitada a obstrução dos caminhos, cabendo aos próprios funcionários ou moradores executarem esse procedimento. Pode-se encontrar instalados os sistemas de alarmes, mas nem sempre estar funcionando, portanto, deve-se verificar se os leds do acionador de alarme estão acesos, pois se estiverem apagados, os alarmes não funcionarão. 0 mesmo deve ser observado quanto às luminárias de emergência, que devem ser verificadas rotineiramente. 
A brigada de incêndio da edificação deve ser treinada por profissionais que tenham no mínimo proficiência no assunto, devendo ser contratadas empresas ou profissionais credenciados pelo Corpo de Bombeiros. Na questão ligada à segurança na utilização de GLP ou GN, cabe aos responsáveis pela edificação requisitar que as empresas fornecedoras do serviço de abastecimento de gás a granel, façam seus testes de estanqueidade de forma periódica, para isto utilizando-se dasorientações contidas nas normas da ABNT.

\section{REFERÊNCIAS}

ABNT. NBR 12693:2010. Sistemas de proteção por extintores de incêndio. Associação Brasileira de Normas Técnicas, 2010

ABNT. NBR 14276:2006. Brigada de incêndio - Requisitos. Associação Brasileira de Normas Técnicas, 2006

ABNT. NBR 15219:2005. Plano de emergência contra incêndio - Requisitos. Associação Brasileira de Normas Técnicas, 2005

ABNT. NBR 9077:2001. Saídas de emergências em Edifícios. Associação Brasileira de Normas Técnicas, 2001

ARACAJU. Lei $\mathbf{n}^{0}$ 13, de 03 de junho de 1966.Código de Obras de Aracaju. Prefeitura Municipal de Aracaju, 1966.

ARACAJU. Lei no 2.765, de 30 de dezembro de 1999. Prefeitura Municipal de Aracaju, 1999.

BERTO, Antonio Fernando. Gerenciamento deSegurança Contra Incêndios em Edifícios.Apostila (Cursodequestões atuais Segurança Contra Incêndios em Edifícios). Universidade de São Paulo,1998.
Mas, sobretudo, o que se reveste de importância, é o entendimento da necessidade do cumprimento das normas de segurança por toda a população, que geralmente não tem ideia do risco que corre cotidianamente devido à prática de burlar a legislação e dar o jeitinho brasileiro, achando que os problemas nunca acontecerão consigo. Vale salientar que o triângulo da segurança deve ser bem definido: as normas, o órgão fiscalizador e a população devem se integrar e desenvolver um sistema de segurança que evite a ocorrência de tragédias.

BRENTANO, Telmo. A segurança contra incêndio no projeto de edificações. 2. ed. Porto Alegre, 2010.

SEITO, Alexandre Itiuet al. A Segurança contra incêndio no Brasil. São Paulo: Projeto, 2008.

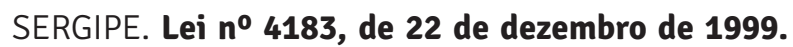
Sistemas de segurança contra incêndio e pânico para edificações. Governo do Estado de Sergipe, 1999.

SILVA, César Henriques Matos e. Espaço Público Político e Urbanidade - 0 caso do centro da Cidade de Aracaju/ César Henrique Matos e Silva, 2009. 
1 Mestrando do Curso de Mestrado em Saúde e Ambiente da Universidade Tiradentes. Graduado em Tecnologia de Segurança do Trabalho, Especialista em Engenharia de Segurança do Trabalho e Consultor Técnico em Segurança do Trabalho. Oficial do Corpo de Bombeiros Militar do Estado de Sergipe. Endereço para correspondência: Rua Lourival do Prado Barreto, 199 - Conjunto Médice II, Aracaju, Estado de Sergipe, Brasil. CEP 49048-380. Telefone celular (79) 9807-4950. E-mail: geovanlimafontes@hotmail.com

2 Doutor em Parasitologia. Graduado em Ciências Biológicas. Professor orientador do Curso de Mestrado em Saúde e Ambiente da Universidade Tiradentes. Pesquisador do Instituto de Tecnologia e Pesquisa. Av. Murilo Dantas, 300, CEP 49032-490, Aracaju, Estado de Sergipe, Brasil.Telefone celular (79) 9192-4614. E-mail: rrmadi@gmail.com

3 Doutora em Geografia/Planejamento Regional. Graduada em Ciências Sociais. Professora orientadora do Curso de Mestrado em Saúde e Ambiente da Universidade Tiradentes. Pesquisadora do Instituto de Tecnologia e Pesquisa. Av. Murilo Dantas, 300, Aracaju, Estado de Sergipe, Brasil. CEP 49032-490. Telefone celular (79) 9972-3466. E-mail: vania@infonet.com.br 